\title{
(Non)Parallel developmental pathways to vertebrate appendage reduction and loss
}

\author{
Samantha Swank ${ }^{1}$, Thomas Sanger ${ }^{1}$, and Yoel Stuart ${ }^{1}$ \\ ${ }^{1}$ Loyola University Chicago
}

November 16, 2021

\begin{abstract}
This is the pre-peer reviewed version of the following article: (Non)Parallel developmental mechanisms in vertebrate appendage reduction and loss, which has been published in final form at https://doi.org/10.1002/ece3.8226. This article may be used for non-commercial purposes in accordance with Wiley Terms and Conditions for Use of Self-Archived Versions.

Appendages have been reduced or lost hundreds of times independently during vertebrate evolution. This suggests that selection routinely favors appendage reduction. How often are the same developmental and genetic pathways used during loss by independent lineages? We reviewed the developmental and evolutionary literatures of appendage reduction in 12 genera spanning fish, reptiles, birds, and mammals. We found that appendage reduction and loss resulted from modified gene expression in each case but one. However, the genes for which expression was modified were rarely shared. Our findings suggest that adaptive loss of complex traits might proceed relatively easily through changes in gene expression along multiple developmental pathways.
\end{abstract}

\section{Hosted file}

Swank_NonParallel_MS_05102021.pdf available at https://authorea.com/users/414443/articles/ 522486--non-parallel-developmental-pathways-to-vertebrate-appendage-reduction-and-loss 